\title{
Helping Others to Find the Leader within Themselves: Training Leadership in Kibungo District Hospital, Rwanda
}

\author{
Christian Ntakirutimana ${ }^{1}$, Innocent Kagabo $^{1}$, Maria Kidner ${ }^{1}$ \\ ${ }^{1}$ University of Rwanda, College of Medicine and Health Sciences, Kibungo School of Nursing \& Midwifery, \\ Rwanda
}

\section{Background}

Improving confidence increases creativity and self-accountability. The core of leadership is developing the skills to assess, guide, and mentor others to develop confidence in their profession. Improving leadership requires specific education. This project was developed after a Needs Assessment of the Kibungo District Hospital and Kibungo School of Nursing and Midwifery.

\section{Purpose}

To design and implement a leadership educational project that would to provide insight and inspiration for personal growth and self-accountability.

\section{Objectives}

To learn and use the concepts of responsibility, authority, and accountability; to build relationships/capacity, and achieving interdependence. These concepts are used for the development of personal values, vision, mission that support their work place's strategic plan.

\section{Description}

A needs assessment (HRH and Kibungo School of Nursing) revealed a need for specific education on leadership. Two faculty members assisted with development and implementation of the project. A framework based on the Creative Health Care Management's Leading an Empowered Organization (LEO) (permission received) was accepted. LEO is a specific leadership based upon developing accountability through improved communication that leads people from beginner to expert in all tasks. A manual was developed for Rwanda with attention to language and ease to understand complex topics. The pilot course was September 25- 27, 2014. Fourteen participants from the Kibungo District Hospital from the emergency room, pediatrics, neonatology, maternity, surgery, internal medicine, mental health, biomedicine, pharmacy, laboratory, and admissions. The course was eighteen presentations plus interactive group discussions. At the course end, participants had a foundation of a personal vision, and value statements that coincided within the hospitals' strategic plan. The LEO framework appears to be understandable to this population. Both the training manual and using group participation format were reported as beneficial. Leadership training can be implemented to both formal and informal leaders.

Key words: leadership, accountably, levels of authority, vision, mission, personal values 